\title{
Quantifying fungal infection of plant leaves by digital image analysis using Scion Image software
}

\author{
C.P. Wijekoon, P.H. Goodwin *, T. Hsiang \\ Department of Environmental Biology, University of Guelph, Guelph, Ontario N1G 2W1, Canada
}

\section{A R T I C L E I N F O}

\section{Article history:}

Received 6 February 2008

Received in revised form 20 March 2008

Accepted 20 March 2008

Available online $\mathrm{xxxx}$

\section{Keywords:}

Scion Image

Image analysis

Anthracnose

Scab

Powdery mildew

Rust

\begin{abstract}
A B S T R A C T
A digital image analysis method previously used to evaluate leaf color changes due to nutritional changes was modified to measure the severity of several foliar fungal diseases. Images captured with a flatbed scanner or digital camera were analyzed with a freely available software package, Scion Image, to measure changes in leaf color caused by fungal sporulation or tissue damage. High correlations were observed between the percent diseased leaf area estimated by Scion Image analysis and the percent diseased leaf area from leaf drawings. These drawings of various foliar diseases came from a disease key previously developed to aid in visual estimation of disease severity. For leaves of Nicotiana benthamiana inoculated with different spore concentrations of the anthracnose fungus Colletotrichum destructivum, a high correlation was found between the percent diseased tissue measured by Scion Image analysis and the number of leaf spots. The method was adapted to quantify percent diseased leaf area ranging from 0 to $90 \%$ for anthracnose of lily-ofthe-valley, apple scab, powdery mildew of phlox and rust of golden rod. In some cases, the brightness and contrast of the images were adjusted and other modifications were made, but these were standardized for each disease. Detached leaves were used with the flatbed scanner, but a method using attached leaves with a digital camera was also developed to make serial measurements of individual leaves to quantify symptom progression. This was successfully applied to monitor anthracnose on $N$. benthamiana leaves. Digital image analysis using Scion Image software is a useful tool for quantifying a wide variety of fungal interactions with plant leaves.
\end{abstract}

(c) 2008 Elsevier B.V. All rights reserved.

\section{Introduction}

Disease severity has often been quantified by visual estimation aided by illustrated diagrammatic scales, such as the drawings of various foliar diseases by James (1971), but visual estimates may be subjective and have limitations in accuracy. Disease severity has also been quantified with leaf area meters (Sutton, 1985) or percent sunlight reflectance and infrared radiation (Nutter et al., 1993). More recently, digital photography has been used to assess fungal infection of fruit (Corkidi et al., 2006), viral infection of leaves (Martin and Rybicki, 1998) and insect feeding (Alchanatis et al., 2000; Chen and Williams, 2006). Schaberg et al. (2003) and Murakami et al. (2005) developed a method for leaf color analysis using the Scion Image software package (Scion Corporation, Frederick, MD) on images of leaves captured with a flatbed scanner. They measured the percentage of green or red in leaves of sugar maple (Acer saccharum), and used these as indicators of plant nutrition and health. Their digital analyses of hundreds of scanned images compared favorably with concurrent spectrophotometric measures of pigments, such as chlorophyll $a$,

\footnotetext{
* Corresponding author. Tel.: +1 519824 4120x52754; fax: +1519 8370442.

E-mail address: pgoodwin@uoguelph.ca (P.H. Goodwin).
}

chlorophyll $b$ and anthocyanins, confirming that their image analysis method can provide a reliable quantitative measure of leaf color and relative concentrations of plant pigments.

Foliar diseases can also cause changes in leaf color thus making it possible that the method of Schaberg et al. (2003) and Murakami et al. (2005) could be adapted to quantify different fungal foliar diseases. To test the method for disease assessment, black and white drawings from a manual of disease assessment keys showing foliar diseases with different disease severities (James, 1971) were digitized using a flatbed scanner, and then analyzed using Scion Image. The disease severities stated in the manual (James, 1971) were then compared to the values determined by Scion Image analysis. Live samples were also tested using leaves of Nicotiana benthamiana inoculated with different concentrations of conidia of the anthracnose pathogen, Colletotrichum destructivum. Then the correlation between the percent diseased tissue measured by Scion Image analysis and the number of leaf spots was determined. The method was also tested on a range of naturally occurring foliar diseases: anthracnose caused by Colletotrichum dematium on Convallaria majalis, scab caused by Venturia inaequalis on Malus domestica, powdery mildew caused by an Oidium sp. on Phlox paniculata and rust caused by Coleosporium asterum on Solidago canadensis. Since the flat bed scanner required that the leaves be 
detached from the plant, an alternative method was developed using images of leaves attached to the plant taken with a digital camera and analyzed by the same method. Anthracnose of $N$. benthamiana was used as an example with the digital camera to quantify disease progression.

\section{Materials and methods}

\subsection{Pictorial key images}

Diagrams of different fungal diseases from the disease key manual of James (1971) were chosen. James (1971) created the manual using images drawn on Cronaflex sheets from diseased leaves, and then the areas on the images were measured with an IBM drum scanner. Blackand-white images from keys 1.10, 1.4, 2.1.1, 2.3, 2.4, 3.2 and 3.3.1 representing corn leaf blight, wheat powdery mildew, black stem of alfalfa, yellow leaf blotch of alfalfa, Stemphylium leafspot of red clover, potato common scab and bean common bacterial blight, respectively, were selected for testing. The images were scanned using a Perfection 1250 U Epson flatbed scanner (Epson Canada Limited, Toronto, ON) at 300 dpi resolution, to obtain at least 1000 pixels of resolution in the larger dimension. The graphics program, Paint Shop Pro7 (Corel Corporation, Ottawa, ON), was used to acquire, import, save and initially process leaf images. Images were saved in uncompressed Tagged Image File Format (TIFF) as input for Scion Image.

\subsection{Diseased leaf tissues}

$N$. benthamiana plants were grown at $16 \mathrm{~h}$ light $\left(150 \mu \mathrm{mol} \mathrm{m} \mathrm{m}^{-2} \mathrm{~s}^{-1}\right.$ at $25^{\circ} \mathrm{C}$ ) and $8 \mathrm{~h}$ dark at $17^{\circ} \mathrm{C}$ to the sixth true-leaf stage. C. destructivum isolate N150P3 (Chen et al., 2003) was cultured on sodium chlorideyeast extract-sucrose agar medium (SYAS) (Mandanhar et al., 1986) at $22{ }^{\circ} \mathrm{C}$ under continuous fluorescent light. Conidia were washed from 7-12 day-old plates to make suspensions of $5 \times 10^{3}, 1 \times 10^{4}, 5 \times 10^{4}$, $1 \times 10^{5}, 5 \times 10^{5}$ and $1 \times 10^{6}$ conidia/mL. Entire plants were sprayed with the suspensions until run-off using an art spray brush connected with an air compressor (Model FP200300AV, Campbell Hausfeld, Harrison, $\mathrm{OH}$ ) (Shen et al., 2001). There were four replicate plants per inoculum concentration. The plants were enclosed in plastic-lined $18.5 \mathrm{~L}$ containers and incubated at room temperature under high humidity.

Fourteen leaves of $C$. majalis with anthracnose, 18 leaves of $M$. domestica with scab, 18 leaves of $S$. canadensis with rust, and 24 leaves of $P$. paniculata with powdery mildew, showing varying levels of disease, were collected from Guelph, Ontario, in August 2006. Leaves were stored at $4{ }^{\circ} \mathrm{C}$ for less than one week before use, and the petioles were removed before scanning.

\subsection{Image capture with the flat bed scanner}

Healthy and infected leaves were scanned as previously described and saved as TIFF files. The images of rust of S. canadensis were directly used in Scion Image analysis without further modification because of the larger difference in color between the green leaf and orange rust pustules. For the other diseases, the images were first adjusted using Paint Shop Pro7 software. For apple scab, brightness and contrast were both increased by $25 \%$; for anthracnose of $C$. majalis, brightness was increased by $20 \%$ and contrast was increased by $65 \%$; for anthracnose of $N$. benthamiana, brightness and contrast were both increased by $25 \%$; and for powdery mildew of $P$. paniculata, images were 'Sharpened More' and then increased in brightness and contrast by $25 \%$ and $75 \%$, respectively.

\subsection{Scion Image processing}

The processing of the digital images in Scion Image was done according to Murakami et al. (2005), except for rust of S. canadensis, where the 003 adjusted color image was selected instead of the 001 adjusted color image when using the image math function. In the method of Murakami et al. (2005), the targeted portion of the leaf is set to a chosen color, and the targeted area is adjusted using the LUT (Look-up table) bar. Therefore, the LUT values are critical for distinguishing healthy from diseased areas in order to quantify them. A standardized minimum and maximum value of the LUT bar was set for measuring each disease.

For the drawings of James (1971), the diseased areas were covered with the top and bottom values of LUT bar set to the maximum $(1 \times 254)$ to obtain the diseased leaf area. For infected plant leaves, the healthy non-diseased leaf area was measured by adjusting the LUT bar. For anthracnose of $N$. benthamiana, the LUT bar was set at $50 \times 254$, for anthracnose of $C$. majalis, the LUT bar was adjusted to $45 \times 254$, and for apple scab of $M$. domestica, the LUT bar was set at $27 \times 254$. For powdery mildew of $P$. paniculata, the LUT bar was set at $1 \times 254$, and for rust of $S$. canadensis, the LUT bar was adjusted to $115 \times 254$. For measuring total leaf area, the LUT bar was set to the maximum $(1 \times 254)$ to cover the entire leaf area, except for the drawings of James (1971) and powdery mildew. In those two cases, the 'Paintbucket' tool in Paint Shop Pro7 was used to color the entire leaf for measuring total leaf area after marking the leaf margins, and then the LUT bar was set to its maximum.

All leaf area measurements were done by selecting the metric scale in Scion Image following the method of O'Neal et al. (2002). The percent diseased leaf area was calculated by subtracting the non-diseased leaf area from the total leaf area for most diseases, because most diseases cause symptoms that are darker than the normal leaf color.

\subsection{Image capture with the digital camera}

Leaves of $N$. benthamiana were inoculated with $1 \times 10^{5}$ conidia/mL of $C$. destructivum (Shen et al., 2001). After inoculation, the plants were placed in a plastic-lined $18.5 \mathrm{~L}$ container, and the leaf to be analyzed for disease was supported with a clear acetate sheet that was attached to the inside of the container. The plants were incubated as previously described.

To capture the image, the incubation container was opened, placed on a lightbox to backlight the plant, and the image of the leaf was captured with a Nikon CoolPix800 digital camera (Nikon Corporation, Tokyo, Japan) fixed at $20 \mathrm{~cm}$ from the leaf. After the images were taken, the container was resealed for further incubation. Images were taken every $4 \mathrm{~h}$ from 0 to $96 \mathrm{HPI}$. With Paint Shop Pro7 software, the

\section{Table 1}

Measurement of diseased leaf area from disease keys of James (1971) using Scion Image

\begin{tabular}{|c|c|c|c|c|c|c|c|c|c|c|c|}
\hline \multirow{2}{*}{$\begin{array}{l}\text { Disease in } \\
\text { James' key }\end{array}$} & \multicolumn{11}{|c|}{ Disease severity in Scion Image by James' key } \\
\hline & 1 & 5 & 10 & 20 & 25 & 50 & 70 & 75 & 80 & $r$ & $\begin{array}{l}P \\
\text { value }\end{array}$ \\
\hline $\begin{array}{l}\text { Clover leaf } \\
\text { spot (2.4) }\end{array}$ & 0.9 & 4.7 & 9.3 & na & 24.1 & 49.5 & na & 72.8 & na & 0.9998 & 0.0001 \\
\hline $\begin{array}{l}\text { Bean bacterial } \\
\text { blight (3.3.1) }\end{array}$ & 0.9 & & 9.6 & na & 25.1 & 50.2 & na & na & na & 0.9999 & 0.0001 \\
\hline $\begin{array}{l}\text { Corn leaf } \\
\text { blight (1.10) }\end{array}$ & 1.3 & 5.2 & na & na & 24.7 & 49.5 & na & na & na & 1.0000 & 0.0001 \\
\hline $\begin{array}{l}\text { Wheat } \\
\text { powdery } \\
\text { mildew (1.4) }\end{array}$ & 1.1 & 5.1 & na & na & 27.0 & 51.4 & na & na & na & 0.9994 & 0.0001 \\
\hline $\begin{array}{l}\text { Potato scab } \\
(3.2)\end{array}$ & 1.1 & 10.2 & na & na & 24.2 & 49.0 & na & na & na & 0.9999 & 0.0001 \\
\hline $\begin{array}{l}\text { Alfalfa black } \\
\text { stem (2.1.1) }\end{array}$ & 1.2 & 7.4 & na & 23.1 & na & 53.4 & na & na & 85.6 & 0.9996 & 0.0001 \\
\hline $\begin{array}{l}\text { Alfalfa yellow } \\
\text { leaf blotch } \\
(2.3)\end{array}$ & 1.7 & 4.2 & na & 19.8 & na & 43.1 & 70.5 & na & 80.7 & 0.9953 & 0.0004 \\
\hline
\end{tabular}

Each Scion Image value is based on a single measurement after scanning and image analysis, and the coefficient of determination $\left(r^{2}\right)$ was calculated between the stated disease severity in James' key, and that calculated with Scion Image analysis. na $=$ not available 
A

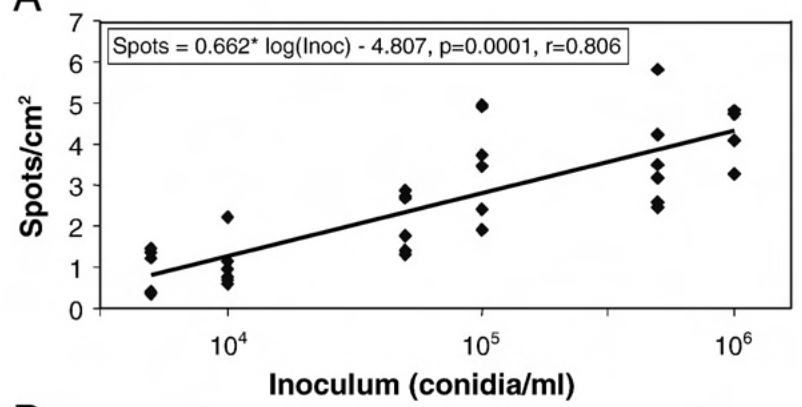

B

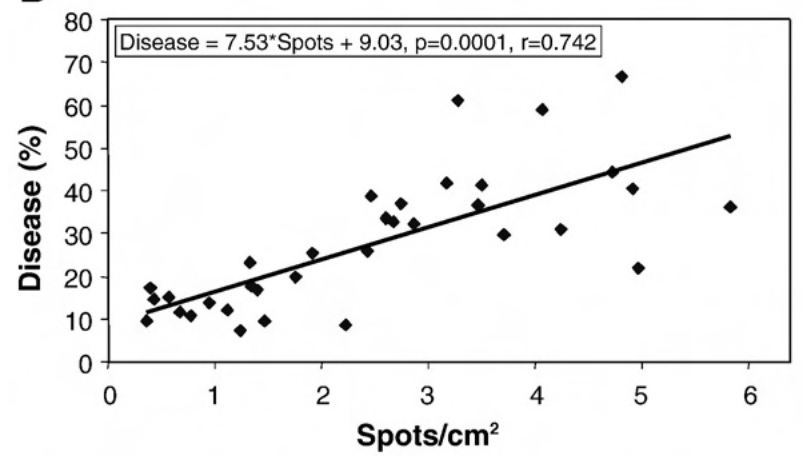

Fig. 1. Regression analyses for the disease assessment of anthracnose caused by Colletotrichum destructivum on Nicotiana benthamiana. Means were pooled from two separate experiments with a total of 15 replications. A) Regression analysis between number of spots per square centimeter and the log of the inoculum concentration of the anthracnose fungus. B) Regression analysis between the number of spots and the percentage of the disease as assessed by Scion Image.

contrast was increased $25 \%$ and the color balance was adjusted to Red 0 , Green -100 and Blue 0 . Analysis by Scion Image was done as previously described for rust of $S$. canadensis.

\subsection{Statistical analyses}

Data were analyzed using correlation analysis or regression analysis in SAS (SAS Institute, Cary, NC). Correlation analyses were done between the level of disease assessed by the Scion Image method, and the level of disease stated in the disease keys of James (1971) for each of seven diseases. Regression analyses were done with data from the disease progression study involving $C$. destructivum inoculated onto $N$. benthamiana. The number of spots per square centimeter was regressed on the level of inoculum applied, and the level of disease assessed by Scion Image analysis was regressed against the number of spots observed.

\section{Results}

\subsection{Disease severity assessment of the keys of James (1971)}

A total of 33 leaf images from seven keys (James, 1971) were scanned and then analyzed with Scion Image to calculate the percent diseased leaf area. These keys are commonly used to aid in the visual assessment of the severity of diseases, such as the seven tested in this study: corn leaf blight, wheat powdery mildew, alfalfa black stem, alfalfa yellow leaf blotch, Stemphylium leafspot of red clover, potato common scab and bean common bacterial blight. The diseased area calculated by Scion Image was then compared to the values given by James (1971) in the keys, and coefficients of correlation $(r)$ were calculated between the values given by James (1971) and those from Scion Image. The $r$ values were above 0.99 for all seven diseases, ranging from $0.9953(P<0.0004)$ for alfalfa yellow leaf blotch to $1.0000(P<0.0001)$ for corn leaf blight (Table 1$)$. The high $r$ values for these seven disease keys indicate that Scion Image analysis can accurately estimate diseased leaf area over a range of disease severities ( 1 to $80 \%$ ), at least by using black and white images from disease assessment keys.
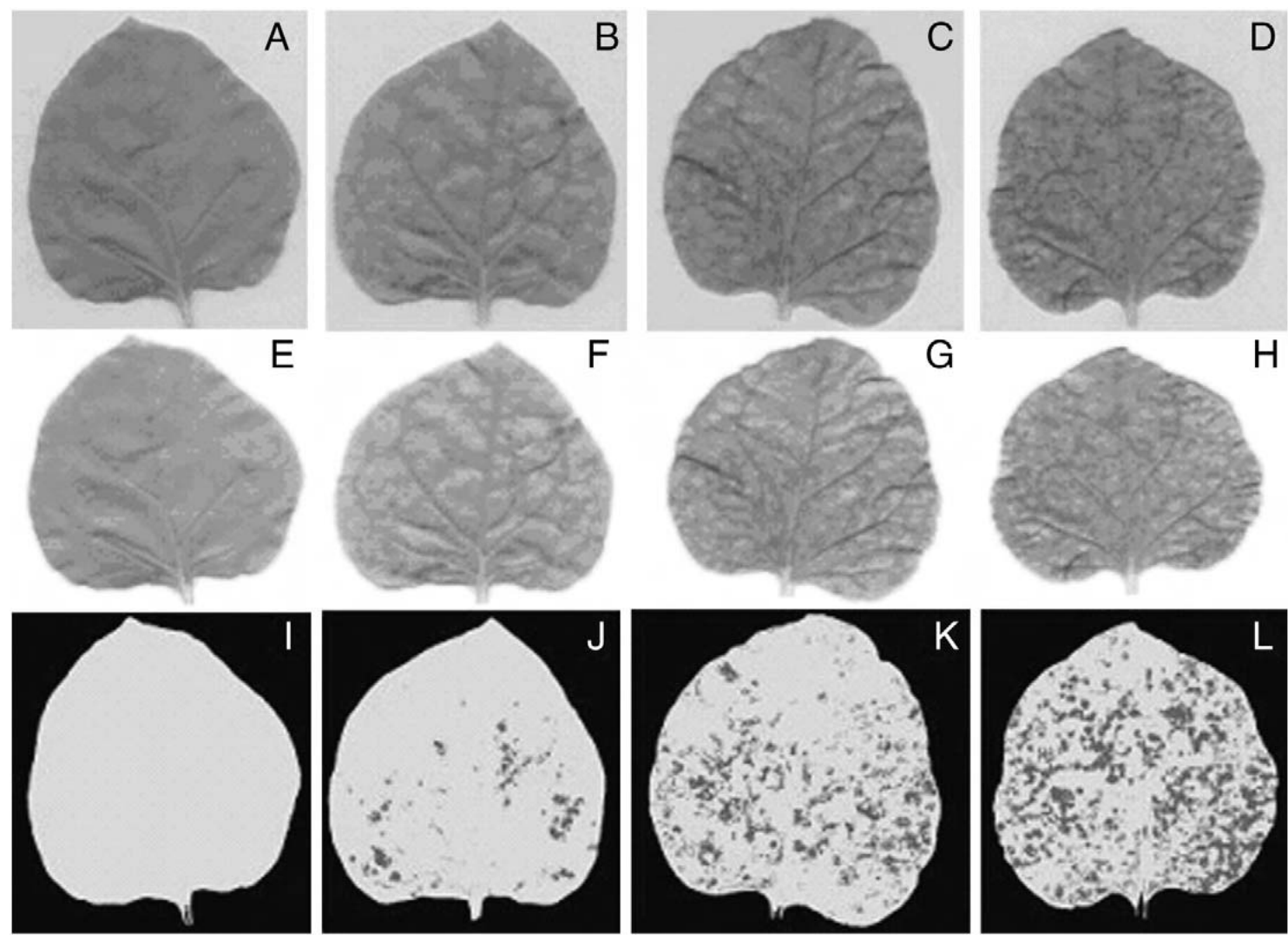

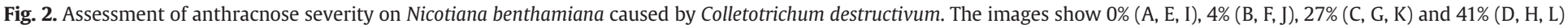

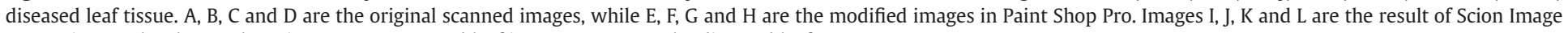
processing. Dark color on the Scion Image processed leaf image represents the diseased leaf area. 

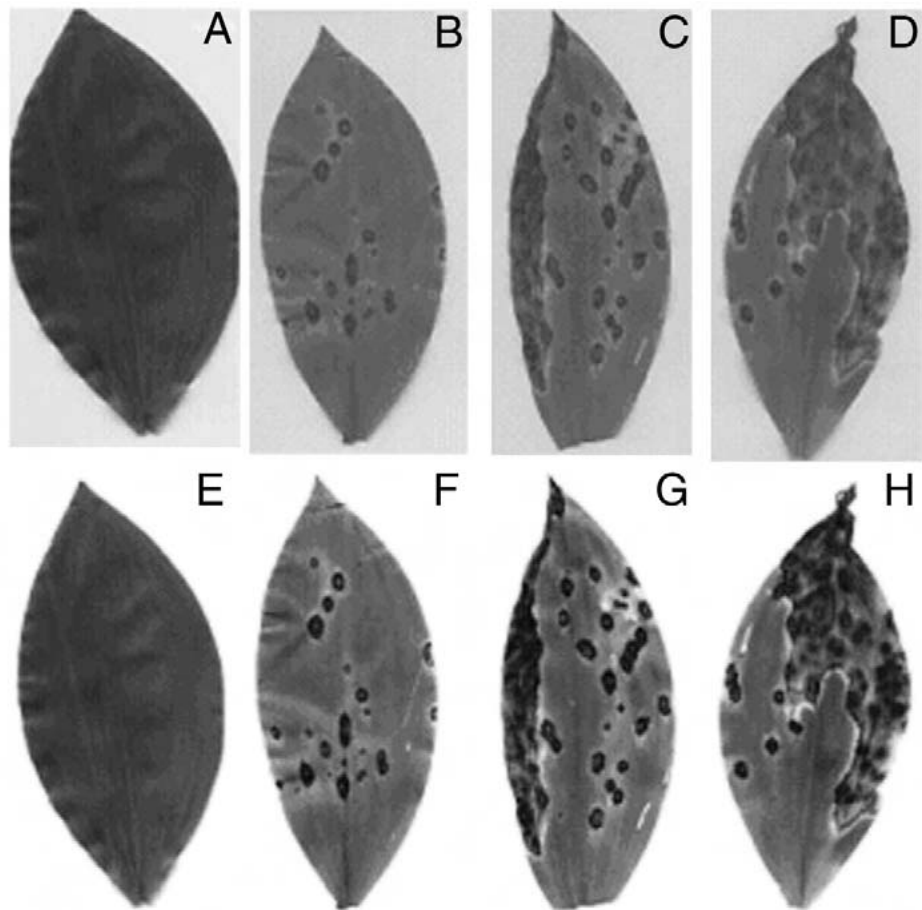

E

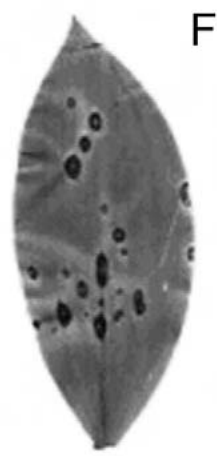

F
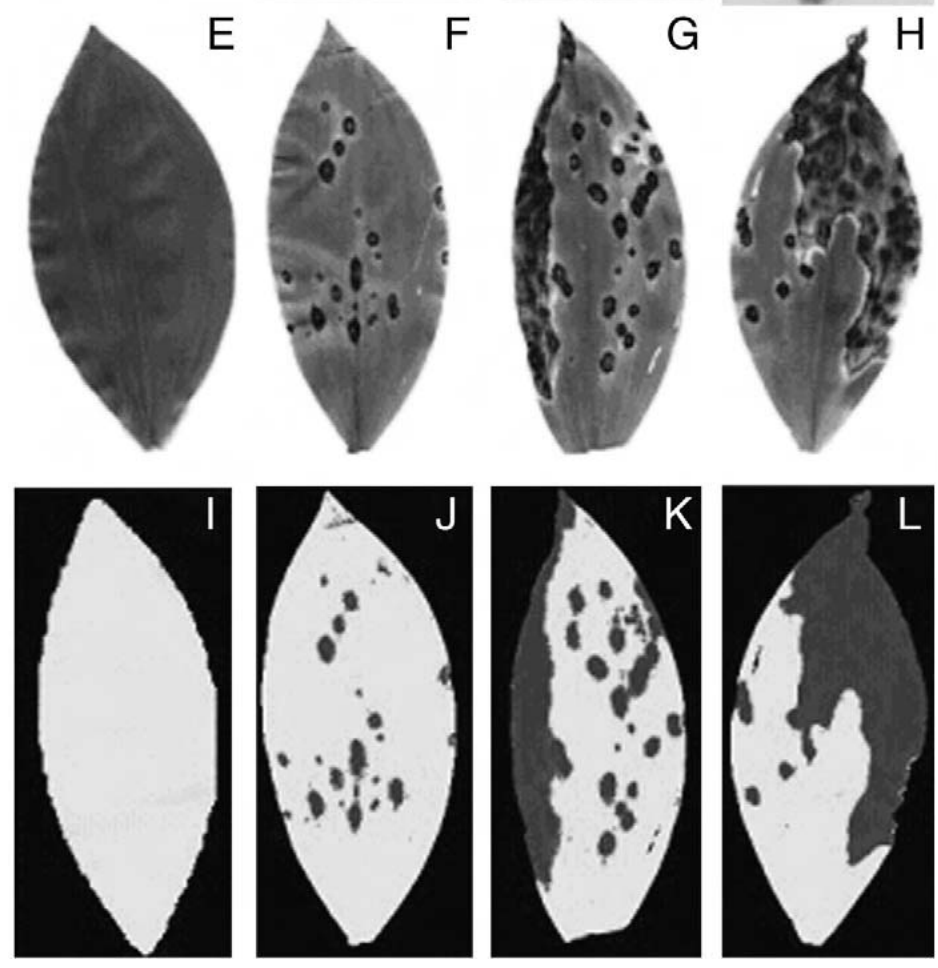

Fig. 3. Measurement of anthracnose severity in Convallaria majalis leaves caused by Colletotrichum dematium. The images show the measurements of $0 \%(\mathrm{~A}, \mathrm{E}, \mathrm{I}), 6 \%$ (B, F, J), 32\% (C, G, K) and 49\% (D, H, L) diseased leaf tissue. A, B, C and D are the original scanned images, while E, F, G and $\mathrm{H}$ are the modified images in Paint Shop Pro. Images I, J, K and L are the result of Scion Image processing. Dark color on the Scion Image processed leaf image represents the diseased leaf area.

\subsection{Disease severity assessment of detached leaves}

Because varying inoculum concentrations primarily affected lesion number rather than lesion size for anthracnose of $N$. benthamiana (Fig. 1A, $r=0.81, P=0.0001$ ), leaves were inoculated with different conidial concentrations of $C$. destructivum and assessed at $96 \mathrm{~h}$ post inoculation (HPI) for the number of visible spots and disease severity as measured by Scion Image analysis. A strong correlation $(r=0.74, P=0.0001)$ was obtained for the percent diseased leaf area estimated by Scion Image analysis and the number of spots on each leaf (Fig. 1B). Fig. 2 shows the original and processed images of four $N$. benthamiana leaves with $0,4,27$ and $41 \%$ diseased area demonstrating the relationship between the lesion areas and the color differences detected and quantified by Scion Image.

Fourteen leaves of $C$. majalis with anthracnose were assessed by Scion Image analysis showing a range of disease severities from $0 \%$ (healthy leaf) to 51\%. Fig. 3 shows four leaves with the original and processed images with disease severities estimated with Scion Image of $0,6,32$ and $49 \%$. Eighteen leaves of $M$. domestica with scab were assessed by Scion Image analysis with scab lesion severities ranging from 0 to 49\%. Fig. 4 shows the original and processed images of four apple leaves with $0,1,15$ and $34 \%$ disease severities determined with Scion Image analysis. Twenty-four leaves of $P$. paniculata infected with powdery mildew were examined and estimated to have disease severities ranging from 0 to $82 \%$ using Scion Image based on the percentage of the leaf area covered with hyphae. Fig. 5 shows original and processed images of four leaves with powdery mildew affected leaf areas of $0,1,17$ and $63 \%$ using Scion Image analysis. Eighteen leaves of $S$. canadensis with rust were examined and found to have disease leaf areas ranging from 0 to $76 \%$ with Scion Image based on the percentage of the leaf covered with uredia. Fig. 6 shows images of four leaves with rust severities estimated to be $3,4,15$ and $65 \%$ with Scion Image.

\subsection{Disease severity assessment of attached leaves over time}

To obtain repeated measurements of disease severity on the same leaf while still attached to the plant, repeated images were taken of individual leaves using a digital camera. An example of the quantification of disease progression over time on an individual leaf is shown in Fig. 7. Before 60 HPI, no symptoms were detected visually, and no diseased leaf area was detected using the digital camera and Scion Image. From 60 to $84 \mathrm{HPI}$, the rate of increase in percent diseased leaf area was constant. During this period, more lesions were observed over time, and the lesions expanded slowly. After $84 \mathrm{HPI}$, the rate of increase in percent diseased leaf area increased, and $65 \%$ diseased leaf area was detected by 96 HPI. From 84 to 96 HPI, the disease mainly increased by enlargement of the lesions. After 96 HPI, the integrity of infected leaves was usually too compromised by the disease to permit further measurements. Fig. 8 shows original images obtained with a digital camera and processed images of a single leaf at 56, 60, 80 and 84 HPI showing symptom development and spread of the fungus in the leaf.

\section{Discussion}

Diagrammatic scales, disease assessment keys and leaf area meters have all been used for disease assessment. More recently, digital cameras or flat bed scanners in combination with computer software has been used to evaluate leaves for color differences including those caused by pathogens. Mycosphaerella leaf disease in Eucalyptus globulus (Pinkard and Mohammed, 2006) and anthracnose caused by C. gloeosporioides of mango fruit (Corkidi et al., 2006) are examples of fungal diseases assessed by digital imagery combined with computer analysis.

$\mathrm{NIH}$ Image is a public domain program developed at the National Institutes of Health (USA) to capture, display, analyze, enhance, measure, annotate and output digital images. A PC version of NIH Image, called Scion Image for Windows, is freely available from Scion Corporation (www.scioncorp.com) and is widely used in the medical, scientific, and educational community. Schaberg et al. (2003) demonstrated that it could also be used to quantify leaf color to determine the relative concentrations of the underlying plant pigments. O'Neal et al. (2002) added a metric scale to the method of Schaberg et al. (2003) to give quantitative data, and Murakami et al. (2005) gave step by step instructions for the method.

Seven of the 19 different diseases in the black and white diagrammatic keys of James (1971) were converted to digital images by scanning with a flat bed scanner. The disease severity values given by James (1971) were compared to the values obtained from Scion Image analysis, and very strong correlations were found, suggesting that the Scion Image method can accurately estimate diseased leaf area from black and white drawings.

Since the drawings in the disease assessment keys were black and white images with very high contrast between diseased area and healthy leaf, it was important to test actual diseased leaves to see if Scion Image analysis could measure differences in leaf color due to fungal infection. A diverse collection of fungal infected leaves with different types of symptoms was used. These included anthracnose of $N$. benthamiana with water-soaked and necrotic spots, anthracnose of 

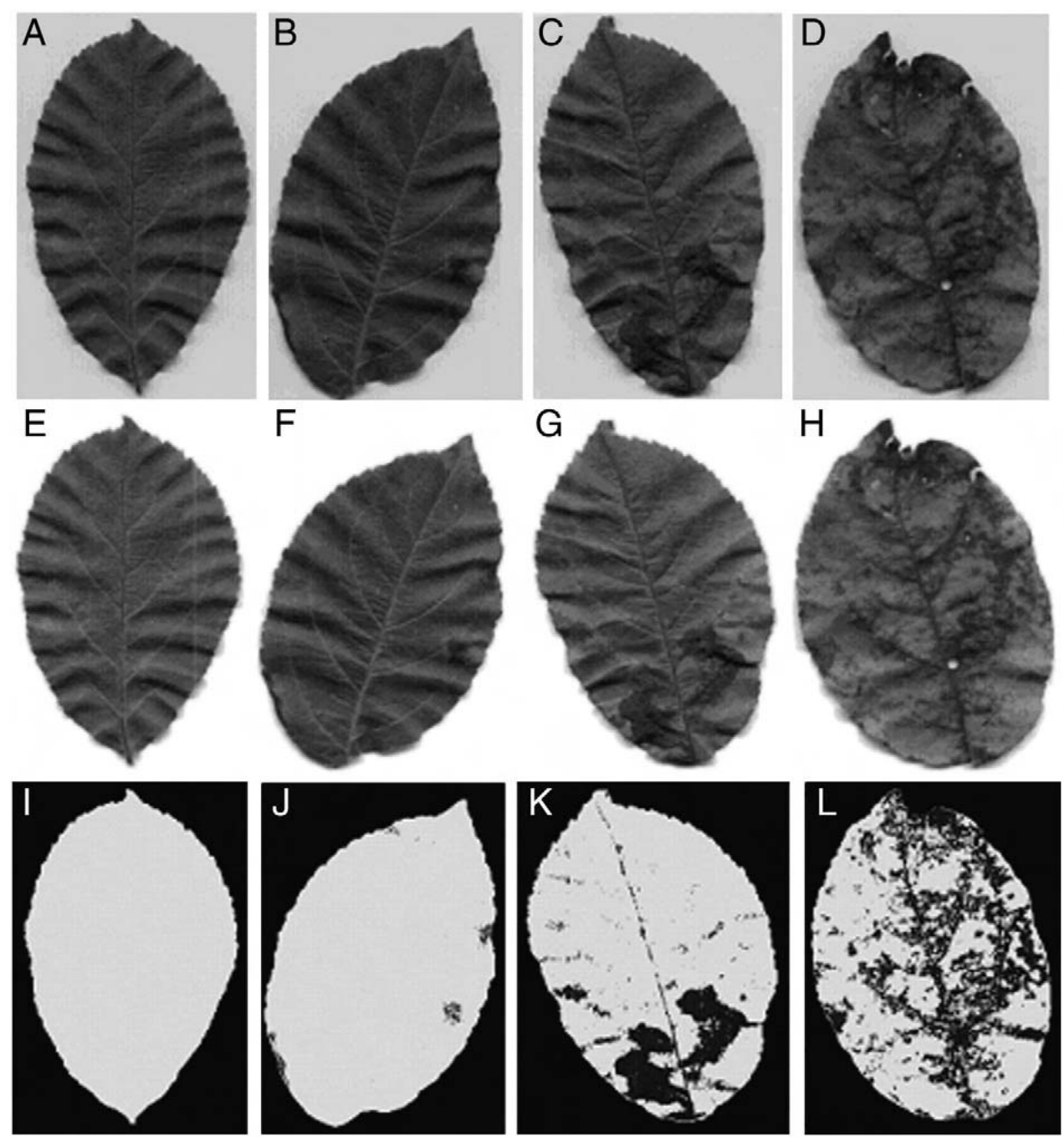

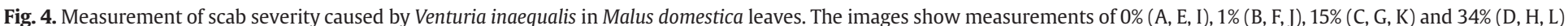

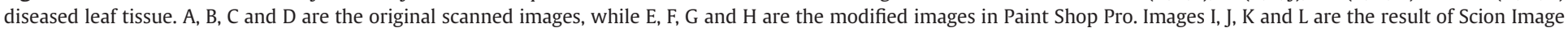
processing. Dark color on the Scion Image processed leaf image represents the diseased leaf area.

C. majalis with brown spots and chlorotic areas, scab of M. domestica with dark brown patches, powdery mildew of $P$. paniculata with white powdery fungal growth on the leaf surface and rust of $S$. canadensis with orange uredia.

A range of disease severities on leaves of $N$. benthamiana inoculated with C. destructivum, causal agent of anthracnose (Shen et al., 2001), was used to compare the estimated disease severity from Scion Image to the number of lesions at 96 HPI. Disease assessment was done at 96 HPI, since the contrast was greatest between the dark lesions and uninfected green tissues. As a hemibiotroph, C. destructivum first grows biotrophically invaginating the initially infected cell with a multi-lobed infection vesicle without producing symptoms (Shen et al., 2001). By approximately $60 \mathrm{HPI}$, thin secondary hyphae arise from multi-lobed infection vesicles, and the fungus kills host cells resulting in water-soaked spots that develop into dark necrotic lesions that could be readily detected by Scion Image analysis at 96 HPI. The use of lesion numbers was considered an appropriate measure of severity because the lesions were relatively similar in size at $96 \mathrm{HPI}$, and increased inoculum levels resulted only in greater lesion numbers rather than larger lesions. The high correlation between the percentage disease severity by Scion Image analysis and the number of lesions in $N$. benthamiana suggests that the method is useful for measuring disease incidence in actual leaves in addition to black and white drawings.

Disease assessment of $N$. benthamiana inoculated with C. destructivum was also done using attached leaves to quantify the development of disease symptoms in the same leaf over time. In order to do this, a digital camera was used instead of a flat bed scanner, and a lightbox was placed below the plants to give high contrast between the lesions and uninfected green tissue. No necrosis was observed during the symptomless biotrophic stage, but by $60 \mathrm{HPI}$, the necrotrophic phase was visible with the appearance of water-soaked spots (Shen et al., 2001). The necrotrophic stage consisted of a slower symptom development phase from 64 to 84 HPI and a faster phase after $84 \mathrm{HPI}$. The slower phase was associated with lesion appearance and enlargement, whereas the faster phase was only associated with lesion expansion. The detection of two phases of necrotrophic development demonstrates one of the advantages of doing serial observations of disease on individual leaves.

The causal agent of anthracnose of $C$. majalis is $C$. dematium (Farr et al., 1989). C. dematium is also a hemibiotroph with a symptomless biotrophic stage when knotted primary hyphae invaginate leaf epidermal and adjacent plant cells (Smith et al., 1999). Secondary necrotrophic hyphae then develop that are associated with the appearance of brown lesions. The symptoms of anthracnose of $C$. majalis are similar to anthracnose of $N$. benthamiana, but the lesions are darker and are also associated with chlorosis. Both the dark lesion and surrounding chlorotic areas could be quantified by Scion Image analysis.

$V$. inaequalis initially grows just under the leaf cuticle producing velvety olive colored spots due to abundant conidial production (MacHardy, 1996). Later, the infected area turns gray or brown as the leaf tissue underneath the mycelium dies and collapses. The diseased apple leaf samples used for Scion Image analysis all had gray- 

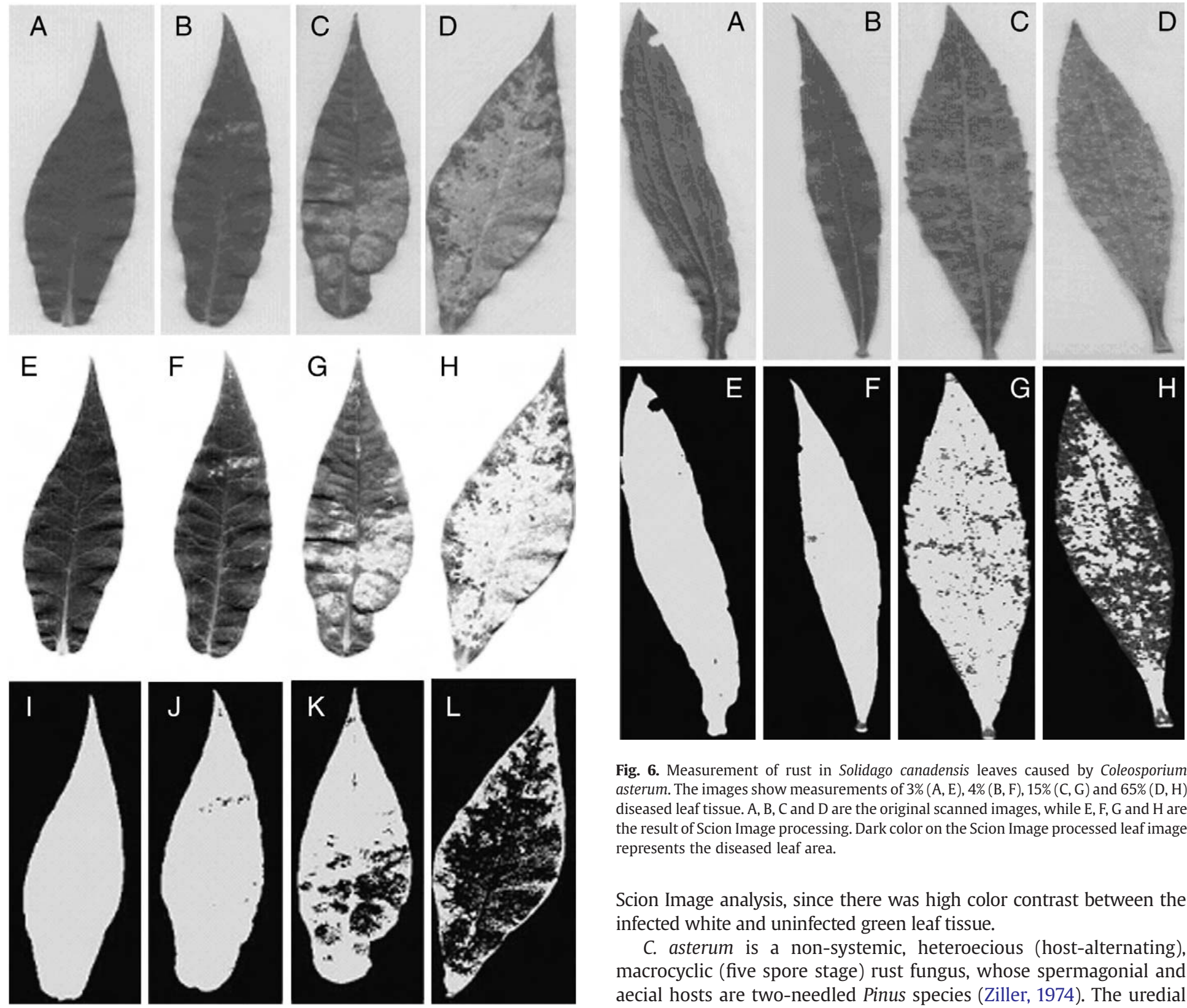

Fig. 6. Measurement of rust in Solidago canadensis leaves caused by Coleosporium asterum. The images show measurements of 3\% (A, E), 4\% (B, F), 15\% (C, G) and 65\% (D, H) diseased leaf tissue. A, B, C and D are the original scanned images, while E, F, G and H are the result of Scion Image processing. Dark color on the Scion Image processed leaf image represents the diseased leaf area.

Scion Image analysis, since there was high color contrast between the infected white and uninfected green leaf tissue.

C. asterum is a non-systemic, heteroecious (host-alternating), macrocyclic (five spore stage) rust fungus, whose spermagonial and aecial hosts are two-needled Pinus species (Ziller, 1974). The uredial host is $S$. canadensis, where the fungus can persist independently of host alternation (Ziller, 1974). C. asterum is a biotrophic pathogen producing haustoria that feed on living host cells of $S$. canadensis with symptoms of orange-yellow pustules containing urediospores that rupture through the epidermis (Heath, 1992). The number and size of

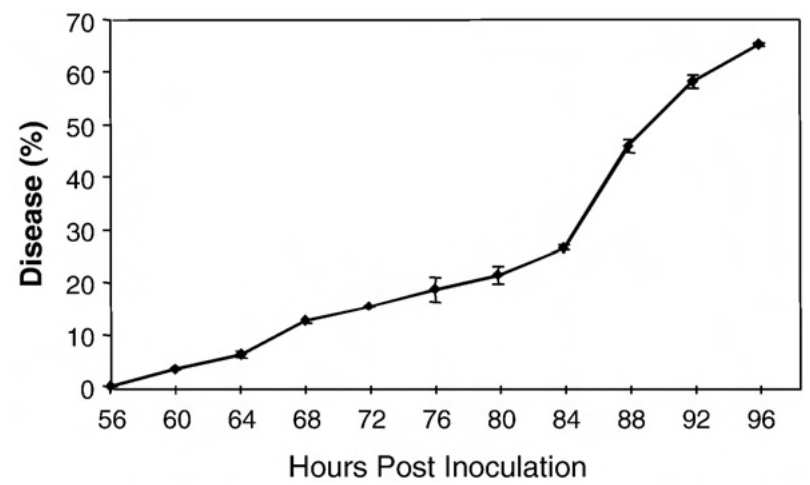

Fig. 7. Scion Image analysis of anthracnose disease development on individual leaves of Nicotiana benthamiana inoculated with Colletotrichum destructivum at $1 \times 10^{5}$ spores/ $\mathrm{mL}$. Percent disease was determined by Scion Image analysis after imaging the leaf every $4 \mathrm{~h}$ with a digital camera beginning at $56 \mathrm{HPI}$. Means are shown with standard error bars calculated from twelve inoculated leaves from separate plants. 

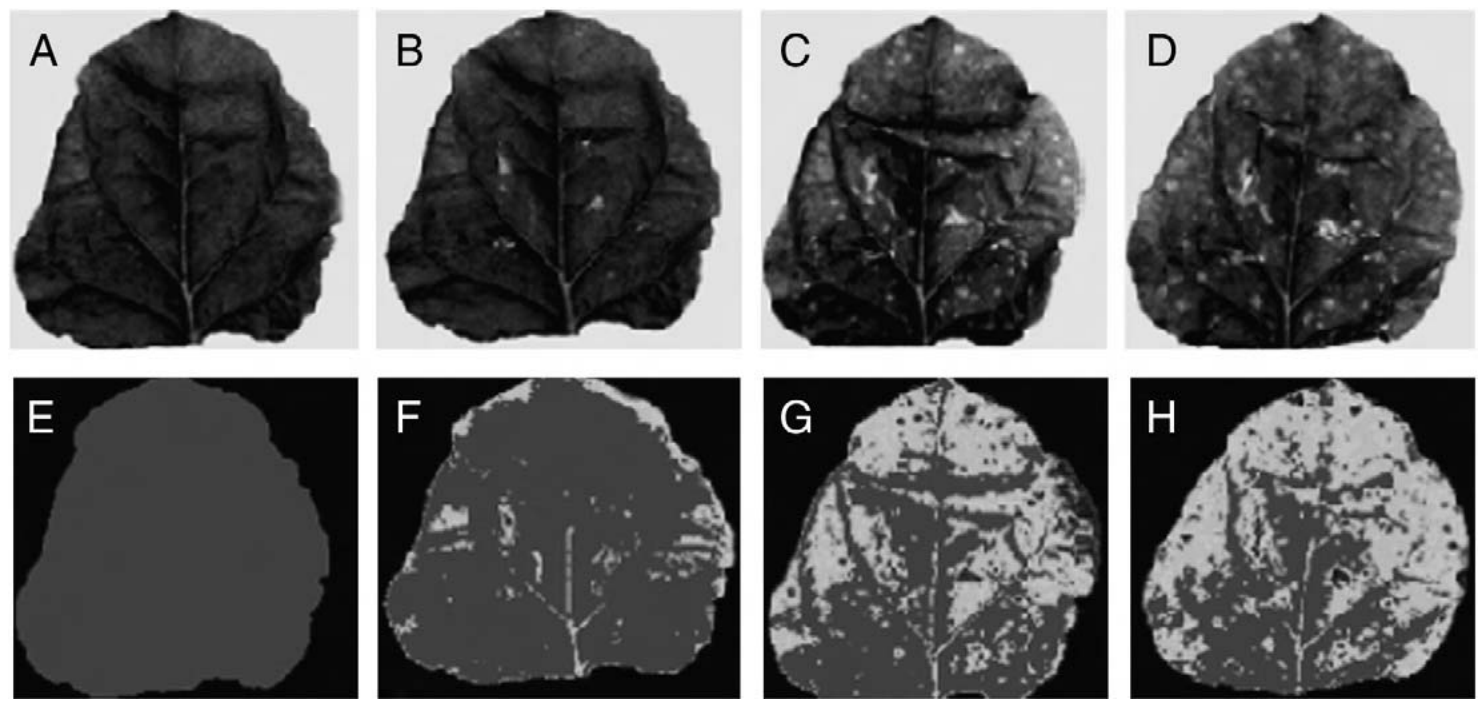

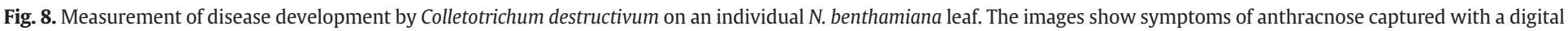

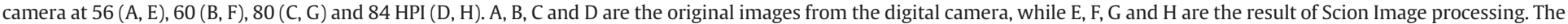
light color on the Scion Image processed leaf image represents the diseased leaf area.

rust pustules can be used to estimate disease severity (Price et al., 2004). In Scion Image analysis, masses of orange urediospores in uredia of different sizes and numbers could be detected as an indication of fungal colonization. The only modification to measure rust with Scion Image was that image 003 was selected instead of image 001 during processing by Scion Image to give greater contrast between the processed colors representing healthy and diseased tissues.

There are other computer programs that can perform digital image analysis for disease assessment. The program, ASSESS: Image Analysis Software for Plant Disease Quantification (APS Press, Saint Paul, MN) was developed to measure leaf area, percent disease, root length and the lesion count (Lamari, 2005). It has been used to quantify rust disease severity on sugarcane and sunflower (Tucker et al., 2001). Image-Pro software (Media Cybernetics, Bethesda, MD) can be used for 2D and 3D image processing, enhancement, and analysis, and Corkidi et al. (2006) used Image-Pro Plus 4.45 software to evaluate the severity of anthracnose of mango fruit, caused by Colletotrichum gloeosporioides. A stepper motor rotated the mango fruit along its longitudinal axis, while a sequence of images were acquired to create a pseudocylindrical 'equalarea' projection of the fruit to detect the high contrast lesions (black spots on a bright yellow background). WINFOLIA (Regent Instruments Inc., www.regentinstruments.com) is designed for leaf morphology and disease analysis. Pinkard and Mohammed (2006) used WINFOLIA to differentiate healthy, discolored and necrotic tissue in leaves of $E$. globulus infected with Mycosphaerella leaf disease. Matrox Inspector 2.2 (Matrox Electronic Systems Ltd., Dorval, PQ) has been used to measure lesion area of cucumber anthracnose caused by Colletotrichum orbiculare (Kwack et al., 2005).

Image analysis programs for disease assessment have been found to have various limitations. One problem with ASSESS, which characterizes lesions based on pixel thresholds, was that it appeared to ignore smaller lesions, which was more evident with sugarcane rust than sunflower rust (Tucker et al., 2001). Image-Pro worked well with simulated infected areas of black tape on a plastic model of mango fruit, but fungal spots on real fruits did not always give such good contrast and sharp edges. This resulted in errors, even though mango anthracnose has much higher contrast (i.e., dark black spots on bright yellow mangoes) than most other plant foliar diseases (Corkidi et al., 2006). Matrox Inspector 2.2 could differentiate and measure lesions, but the program could not detect lesions clearly because it could not distinguish lesion margins. Therefore, the Magic Wand and Edit tools of Photoshop 6.0 had to be used to draw the lesion margins of cucumber anthracnose, which could introduce errors (Kwack et al., 2005).
This study has shown that Scion Image analysis can be used to assess a wide variety of fungal foliar diseases, such as powdery mildew, rust, anthracnose and scab. This method can be used for detached leaves with a flat bed scanner as well as attached leaves with a digital camera. It takes less time compared to diagrammatic scales and should be more accurate than visual estimation, and thus it appears to meet the requirement of a desirable disease assessment method, which is to provide accurate and precise measurements of disease (Nutter et al., 2006). In addition, comparable image analysis software costs between \$US 200 to 1500, while Scion Image software is freely available to download from www.scioncorp.com.

\section{Acknowledgements}

Funding for this study was provided by the Natural Science and Engineering Research Council of Canada and the Ontario Ministry of Agriculture, Food and Rural Affairs. We wish to thank Dugan Maynard for his technical assistance.

\section{References}

Alchanatis, V., Navon, A., Glazer, L., Levski, S., 2000. An image analysis system for measuring insect feeding effects caused by biopesticides. J. Agric. Eng. Res. 77, 289-296.

Chen, Y., Williams, K.A., 2006. Quantifying western flower thrips (Frankliniella occidentalis Pergande) (Thysanoptera: Thripidae) damage on ivy geranium (Pelargonium peltatum (L.) L'Her ex Ait.) (Geraniaceae Juss.) with Adobe Photoshop and Scion Image software. J. Kans. Entomol. Soc. 79, 83-87.

Chen, N., Hsiang, T.H., Goodwin, P.H., 2003. Use of green fluorescent protein to quantify the growth of Colletotrichum during infection of tobacco. J. Microbiol. Methods 53, 113-122.

Corkidi, G., Balderas-Ruíz, K.A., Taboada, B., Serrano-Carreón, L., Galindo, E., 2006. Assessing mango anthracnose using a new three-dimensional image-analysis technique to quantify lesions on fruit. Plant Pathol. 55, 250-257.

Farr, D.F., Bills, G.F., Chamuris, G.P., Rossman, A.Y., 1989. Fungi on Plants and Plant Products in the United States. APS Press, St. Paul, MN, USA.

Green, J.R., Carver, T.L.W., Gurr, S.J., 2002. The formation and function of infection and feeding structures. In: Belanger, R.R., Bushnell, W.R., Dik, A.J., Carver, T.L.W. (Eds.), The Powdery Mildews: A Comparative Treatise. APS Press, St. Paul, MN, USA, pp. 66-82.

Heath, M.C., 1992. Host species specificity of the goldenrod rust fungus and the existence of rust. Can. J. Bot. 70, 2461-2466.

James, W.C., 1971. An illustrated series of assessment keys for plant diseases, their preparation and usage. Can. Plant Dis. Surv. 51, 39-65.

Kwack, M.S., Kim, E.N., Lee, H., Kim, J.-W., Chun, S.-C., Kim, K.D., 2005. Digital image analysis to measure lesion area of cucumber anthracnose by Colletotrichum orbiculare. J. Gen. Plant Pathol. 71, 418-421.

Lamari, L., 2005. ASSESS: Image Analysis Software for Plant Diseases. APS Press, St. Paul, MN, USA.

MacHardy, W.E., 1996. Apple Scab: Biology, Epidemiology and Management. APS Press, St. Paul, MN, USA. 
Mandanhar, J., Hartman, G., Sinclair, J., 1986. Colletotrichum destructivum, the anamorph of Glomerella glycines. Phytopathology 76, 282-285.

Martin, D.P., Rybicki, E.P., 1998. Microcomputer-based quantification of maize streak virus symptoms in Zea mays. Phytopathology 88, 422-427.

Murakami, P.F., Turner, M.R., Van den Berg, A.K. and Schaberg, P.G. (2005) An instructional guide for leaf color analysis using digital imaging software. United States Department of Agriculture Publication. Tech. Rep. NE-327.

Nutter Jr., F.W., Gleason, M.L., Jenco, J.H., Christians, N.C., 1993. Assessing the accuracy, intra-rater repeatability and inter-rater reliability of disease assessment systems. Phytopathology 83, 806-812.

Nutter Jr., F.W., Esker, P.D., Rosalee, A.C.N., 2006. Disease assessment concepts and the advancements made in improving the accuracy and precision of plant disease data. Eur. J. Plant Pathol. 115, 95-103.

O'Neal, M., Landis, D.A., Isaacs, R., 2002. An inexpensive, accurate method for measuring leaf area and defoliation through digital image analysis. J. Econ. Entomol. 195, 1190-1194.

Pinkard, E.A., Mohammed, C.L., 2006. Photosynthesis of Eucalyptus globulus with mycosphaerella leaf disease. New Phytol. 170, 119-127.
Price, J.S., James, D.B., Clay, K., 2004. Genotype, environment, and genotype by environment interactions determine quantitative resistance to leaf rust (Coleosporium asterum) in Euthamia graminifolia (Asteraceae). New Phytol. 162, 729-743.

Schaberg, P.G., Van Den Berg, A.K., Murakami, P.F., Shane, J.B., Donnelly, J.R., 2003. Factors influencing red expression in autumn foliage of sugar maple trees. Tree Physiol. 23 325-333.

Shen, S., Goodwin, P.H., Hsiang, T., 2001. Hemibiotrophic infection and identity of the fungus, Colletotrichum destructivum, causing anthracnose of tobacco. Mycol. Res. $105,1340-1347$.

Smith, J.E., Korsten, L., Aveling, T.A.S., 1999. Infection process of Colletotrichum dematium on cowpea stems. Mycol. Res. 103, 230-234.

Sutton, J.C., 1985. Effectiveness of fungicides for managing foliar diseases and promoting yields of Ontario winter wheat. Phytoprotection 66, 141-152.

Tucker, C.C., Chakraborty, S., Wilson, P.A., 2001. Configuration of "ASSESS" to measure rust severity on sugarcane and sunflower. Acta Hort. 562, 397-400.

Ziller, W.G. (1974) The tree rusts of western Canada. Forest Service, Vancouver, Canada, Publications No. 1329, 72-76. 